\title{
A fenomenologia de Husserl como herança científica
}

\author{
Fabricio Klain Cristofoletti \\ Orientador: Prof. Dr. Marco Aurélio Werle \\ PET-USP
}

Frisou-se com muita ênfase (como Sartre, por exemplo) o modo como, depois da fundamentação que Husserl faz da fenomenologia transcendental nas "Idéias I", esta filosofia se encontraria ainda ingenuamente nos limites da crítica da possibilidade do conhecimento, como ela tenderia a permanecer puramente anterior ao mundo no sentido bruto, como Husserl cairia ainda em um subjetivismo ou idealismo. Ora, talvez fosse igualmente interessante ver o caminho inverso das leituras existencialistas. Em outras palavras, o objetivo aqui não é mais uma vez examinar o já saturado legado de Husserl na área da metafísica ou ontologia, mas ver suas repercussões no âmbito da lógica. Seria ver como antes do nascimento e de seu primeiro desen-

' HUSSERL, E. Ideen zu einer reinen Phänomenologie und phänomenologischen Philosophie. In Jahrbuch für Philosophie und phänomenologische Forschung, Halle, Max Niemeyer, 1913, p. 1-323. Obra dividida em três volumes que apresenta a fenomenologia pelo seu princípio e com exemplos resumidos; bem como a idéia da fenomenologia transcendental. As Idéias II estuda os problemas da constituiçäo da coisa física, já as Idéias III funda a filosofia primeira sobre a fenomenologia. 
volvimento na "Idéia da Fenomenologia" (1907) ${ }^{2}$ e na "Filosofia como ciência de rigor" (1911), ${ }^{3}$ Husserl reivindicava justamente que a ingenuidade seria não observar primeiramente a necessidade de críticas do conhecimento (que faltava tanto à psicologia da época), a elucidação total dos obscuros fenômenos lógicos e matemáticos que habitavam a filosofia, mas que, se adequadamente remanejados, poderiam ainda continuar como instrumentos úteis à edificação de um âmbito filosófico essencial e rigorosamente científico.

Husserl enxergava o esforço dos filósofos psicologistas de sua época na tentativa de encontrar um fundamento material ou uma realidade efetiva (wirkliche Wirklichkeit) para manipular empiricamente o psíquico, mas se realmente desejamos a filosofia (que não se leia por extensão tudo que é seguido dela, como as ciências objetivas, por exemplo) como um estudo rigoroso, deve-se primeiro achar o fundamento de toda ciência possível, o método e seu correspondente campo de estudo. Comecemos a entender como esses pontos serão em termos gerais desde da "Filosofia da Aritmética" (1891) ${ }^{4}$ - apenas em forma de embriões e ainda sob influência de Brentano; até os seus últimos livros - já como fenomenologia transcendental, respectiva-

2 Idem, Die Idee der Phänomenologie. Fünf Vorlesungen. Editado por Walter Biemel. Hague, Martinus Nijhoff, 1973. Como uma introdução aos Fragmentos da fenomenologia e da crítica da razão, essas cinco lições tinham sido pronunciadas por Husserl em Gotingën, de 26 de abril a 2 de maio de 1907. Husserl naquele momento passava por crises acadêmicas que o fizeram repensar sua situação diante da filosofia.

3 Idem, "Philosophie als strenge Wissenschaft." In: Logos 1, Tübingen, 1910-11, p. 289-341.

4 Idem, Philosophie der Arithmetik. Pyschologische und logische Untersuchungen. Erster Band. Halle-Saale, C.E. M. Pfeffer (Robert Stricker), 1891. Brentano foi o mestre de Husserl em filosofia, nasceu em 1838 e morreu 1917. Investigou as questōes metafísicas por análises lógico-lingüísticas. Seus estudos no campo da psicologia apresentaram o conceito de "intencionalidade", que teria uma influencia direta sobre Husserl, a qual define a apreensão não como um conteúdo da consciência, mas como sendo o visar, o referir-se a algum objeto. 
mente, os conceitos de fenomenologia, descrição e redução fenomenológicas e o de consciência. Mas a intenção aqui é apenas trilhar parte desse caminho invertido, é ver como progrediu o pensamento husserliano de 1891 a 1911, da "Filosofia da Aritmética" até "A idéia da fenomenologia" e "Filosofia como ciência de rigor" e deixar para outra ocasião o ingresso de Husserl à teoria definitiva da fenomenologia como filosofia transcendental, análise esta que depende da leitura dos livros posteriores. Devido à brevidade deste artigo, não faremos, infelizmente, um exame das "Investigações Lógicas" (1900-01), pois esta obra, apesar de se situar dentro do período escolhido, é demasiado extensa para abordarmos suficientemente as suas relações com as outras obras citadas, postergando-se esse estudo para uma outra ocasião.

Como então se poderia elucidar a filosofia de Husserl sem focar as interpretaçōes ontológicas de filósofos posteriores inspiradas na fenomenologia? A resposta parece ser a necessidade de deslocar o foco da metafísica para um olhar interior à lógica husserliana.

Vejamos como essas três obras citadas se implicam reciprocamente. Lendo a "Filosofia como ciência de rigor", percebe-se claramente que o objetivo de Husserl é reorientar a filosofia atual a um molde científico. Que se entenda por isso que o autor conceberá a filosofia como inseparável da idéia de ciência geral, da idéia de um sistema ou estrutura geral absolutamente necessária e clara no maior grau possível de imanência. ${ }^{6}$ A filosofia, para Husserl, deveria ser cientificamente rigorosa antes de tudo. Deve-se enfatizar aqui a generalidade e o rigor que a filosofia científica exige, para, sobretudo, evitar mal-entendidos. Um mal-entendido seria filiar o autor junto a filósofos da modernidade que já reclamavam da falta de cientificidade na

${ }^{5}$ Idem, Logische Untersuchungen. Halle, Max Niemeyer, 1900-1901.

6 "Imanência" é utilizada aqui porque é o nome da região que a fenomenologia estudará depois que Husserl tiver colocado o "mundo natural" e a transcendência entre parênteses pela "redução fenomenológica" 
filosofia medieval. Por que Husserl quer ainda reivindicar essa idéia de Ciência? Parece que, de algum modo, a raiz disso foi alguma novidade ímpar na filosofia e que está explícita, por exemplo, na obra "Idéia da Fenomenologia" A novidade que Husserl descobriu foi em parte devido à situação em que se encontrava a filosofia na época e também pela herança de Brentano, a "intencionalidade", que permitia seu mestre se separar do empirismo inglês e do kantismo acadêmico (pois ele distinguia ali a lógica da psicologia).

Nossa investigação se iniciará pela primeira parte da novidade. A filosofia no começo do século XX vinha deixando-se tomar substancialmente sua importância pela ascensão da psicologia como ciência do psíquico desde os estudos de J. St. Mill até os de Hamilton, Sigwart, Wundt, etc. O prestígio estava se perdendo por causa de um crescente psicologismo dentro da filosofia, os filósofos estavam sendo tomados por uma atitude naturalista e mais precisamente, disse Husserl, de uma visão psicologista. $\mathrm{O}$ psicologismo propunha uma ciência do psíquico fundada e realizada nos dados naturais, físicos e empíricos da mente. Aliás, não foram somente os intelectuais psicologistas que exerciam essa atitude natural, mas todo o pensamento moderno desde Galileu permaneceu nela; alguns filósofos mais abstratamente, como Descartes, ou mais na vertente empirista, como Hume e Locke. Mas todos, sem exceção, sempre cindiam sujeito e objeto, entendimento e sensibilidade ou em uma só frase: concebiam o objeto como um conteúdo do sujeito. $\mathrm{O}$ psicologismo se limita a estudar as premissas naturais e empíricas, pretendendo, assim, meramente substituir a Filosofia pelas leis exatas do Tempo e do Espaço, porque a Natureza seria precisamente a unidade destes dois elementos. Ele se esforça em transformar toda a idealidade dos princípios lógico-formais em leis naturais do pensamento. Isso, para Husserl, é um contra-senso, pois é impossível a consciência, o psíquico e as idéias serem compreendidos a partir de experiências e juízos empíricos. Se aceita a linha de pensamento naturalística, a conseqüência presumível de qualquer mente sensata seria que a "única coisa razoável seria ne- 
gar a própria Razão", 7 como no ceticismo antigo. Husserl entende então que "pelos seus pontos de partida, toda a ciência natural é ingênua" 8

Nota-se, com isso, que Husserl fará uma radical crítica ao psicologismo e à atitude natural que pode ser encontrada principalmente na "Idéia de Fenomenologia", pois lá aparece a chave fundamental para a filosofia husserliana: a intencionalidade. Embora já tenhamos comentado, mesmo que ainda indiretamente, desde o começo do texto, os pontos principais pontos desta obra, talvez seja melhor antes precisar um pouco mais a crítica ao psicologismo na matemática, que Husserl realiza em um livro anterior, a "Filosofia da Aritmética", de 1891. Essa análise parece ser adequada para o que foi acima comentado, pois Husserl caracterizará justamente a obra como um "preparar somente, em uma série de 'pesquisas psicológicas e lógicas', os fundamentos científicos para uma tal construção a vir mais tarde" ${ }^{9} \mathrm{O}$ intuito geral do livro seria "a questão de saber se é o domínio da enumeração, ou qual é o domínio conceitual, se é outro, que comanda a aritmética geral no sentido primeiro e originário", "elucidar completamente, do ponto de vista lógico, o sentido verdadeiro da aritmética em geral" e "desenvolver ainda no tomo II uma nova teoria filosófica da geometria euclidiana, cujas idéias fundamentais têm uma estreita relação com as questões que devem ser discutidas a este respeito" 10 Ora, Husserl não se esforçou para publicar o tomo II e deve haver uma razão forte pela qual a filosofia matemática tenha conduzido Husserl a uma vereda ainda não explorada: precisamente a idéia de fenomenologia. Vejamos então somente o que essas pesquisas teriam a fornecer não à aritmética, mas também à filosofia fenomenológica.

7 Edmund HUSSERL. Filosofia como ciência de rigor, Coimbra, Ed. Atlântida, 1952, p. 11.

${ }^{8}$ Ibidem, p. 14.

9 Idem, Philosophie de l'Aritméthique, Paris, Presses Universitaires de France, 1972, p. 3.

${ }^{10}$ Ibidem, p. 6. 


\section{Análise da "Filosofia da Aritmética"}

Sabe-se muito bem que a matemática foi a inspiração de Husserl a estudar filosofia, principalmente o conceito de "número", o qual passava por grandes novidades enquanto ele ainda era estudante. A primeira abordagem feita sobre o conceito de "número" aparece pelo que a linguagem comum nos indicaria: os números se formam pela enumeração geradora de gêneros.

A enumeração mais simples seria a feita com os números de base (um, dois, etc.), depois haveria a enumeração de gênero (de uma única espécie, de duas espécies, etc.), e uma mais complexa seria a dos números de repetição (uma vez, duas vezes, etc.).

Embora alguns intelectuais como W. R. Hamilton e v. Helmholtz reivindiquem "para os números ordinais a superioridade sobre as enumerações, de tal forma que estas últimas deveriam surgir somente de aplicações especiais dos primeiros", ${ }^{11}$ diz Husserl que as enumerações só podem ser concebidas por uma idéia de quantidade, em outras palavras, de contagem indeterminável por direito.

Mas a indefinição da quantidade ainda não é o fundamento da formação dos números, há ainda a "ligação coletiva" Antes da "enumeração" - a qual é concretamente determinada - existe a abstração anterior sem limite algum, a "abstração quantitativa"; mas há ainda um tipo de abstração mais anterior ao âmbito de qualquer marca distintiva da quantidade: a "ligação coletiva" A "ligação coletiva", ou em outras palavras, "os suportes da abstração, eles não são esses conteúdos singulares, mas são os conjuntos concretos enquanto todos [composições, também dirá Husserl], nos quais os conteúdos singulares se encontram reunidos" 12 "É cometer um mal-entendido dizer que os conteúdos singulares se compõem simplesmente de conteúdos singulares", o que está presente antes deles é a ligação desses elemen-

\footnotetext{
"Ibidem, p. 13. No português o termo mais adequado seria "numeral ordinal". ${ }^{12}$ Ibidem, p. 18.
} 
tos. Quantidade e ligação coletiva não se confundem porque a quantidade é um processo abstrativo posterior e diferente, a quantidade "são essas ligações similares [similitude (Gleichartigkeit)], em todos os casos onde é questão de quantidades, que formam as bases da construção do conceito geral da quantidade" ${ }^{13}$ Com efeito, esse todo com o qual a ligação coletiva faz uma composição que é concreta, essa "concretude" não é conteúdo e nem surge como conteúdo na representação "como uma parte particular e notável por ela mesma. $\mathrm{O}$ todo é concreto, mas não é um dado concreto, o todo é um continuum" ${ }^{14}$ Os exemplos concebidos por Husserl são "as conexões entre os pontos de uma linha, os momentos de uma duração, as qualidades sonoras de um 'movimento sonoro', etc" 15

Husserl preferirá então analisar a formação do número como processo de abstração, inspirado nessa idéia de "ligação coletiva", que pode ser feito de maneira própria ou simbólica, como dizia Brentano. É importante frisar esse "ou", porque embora Husserl comece primeiramente por examinar a base e a origem psicológica dos números próprios, ou seja, dos conjuntos de objetos singulares concretos dados de maneira determinada por eles mesmos um por um e agrupados em uma coleção; na verdade qualquer objeto representado singularmente ou genericamente pode ser abstraído simbolicamente. Não há limite para a abstração simbólica (tanto é verdade que se veja o desenvolvimento da aritmética pura).

É na aritmética que Husserl vê de forma muito clara essa falta de limite e é justamente esse ponto que a psicologia errou na tentativa de supri-la. A psicologia concordava ainda (e na matemática Frege foi um dos que também concordaram) com a escola empirista de J. St. Mill, o qual definia o "número" como um fato físico. Segundo Mill, "é impossível negar que duas maçãs são fisicamente separáveis de três,

\footnotetext{
${ }^{13}$ Ibidem, p. 22.

14 Ibidem, p. 23.

${ }^{15}$ Idem.
} 
dois cavalos de um, e assim por diante, de tal maneira que eles são, cada um, um fenômeno visível, tangível e diferente" ${ }^{16}$ Ora, o apelo ao físico só pode ser um erro grosseiro, porque "duas maçãs podem sem dúvida ser fisicamente separáveis de três; mas dois juízos não são de três, nem duas possibilidades de três, etc" ${ }^{17}$

O autor, contudo, reconhece haver uma possível objeção à sua teoria: se as ligações coletivas são composições que formam os conteúdos, elas também devem formar a quantidade (o conjunto de conteúdos), mas a quantidade já não seria também uma composição de um todo, uma unificação, uma ligação, não só haveria nessas teses uma sinonímia de conceitos? A solução de Husserl será importantíssima.

Quando se pergunta qual [é] o gênero de unificação que há no conjunto, a resposta mais curta consiste no reenviar diretamente aos fenômenos ${ }^{18}$ (grifo nosso).

Husserl depois desenvolve as três objeções possíveis contra sua idéia e as critica. Vamos aqui apenas citá-las: a da "unificação de fenômenos parciais em cada consciência total", ${ }^{19}$ a da "simultaneidade do Tempo" e da "coleção sucessiva única" A crítica husserliana é resumidamente que a tese sobre a consciência é falsa porque os fenômenos não são conteúdos que se identificariam a uma consciência, nem mesmo se fossem imediatos, parciais ou irrefletidos. "Não se tem o direito de confundir representações presentes [pretenso fenômeno

${ }^{16}$ Idem.

${ }^{17}$ Como veremos mais adiante, a parcialidade para Husserl não é uma anterioridade que visaria intencionalmente o todo, porque ela já é um tipo de interesse ou intenção de segundo grau (a separação ou distinção). Essa tese, a da consciência como já sendo um fenômeno não refletido, assemelha-se muito àquela usada por Sartre mais tarde, a da "consciência irrefletida" Cf. p.26-8 da "Filosofia da Aritmética".

${ }^{18}$ Edmund HUSSERL, Philosophie de l'Aritméthique, p. 33.

${ }^{19}$ Idem, p. 36. 
parcial ou imediato] com representações de alguma coisa presente [fenômeno verdadeiramente parcial], nem de representações passadas com representações de alguma coisa do passado" ${ }^{20}$ A rejeição das duas outras teses - as quais uma é derivável da outra - é que "nós não fazemos sempre atenção às relações temporais, e é mesmo por essa razão que somos capazes de distinguir entre uma quantidade pura e simples e uma quantidade de conteúdos consecutivos (ou simultâneos) [recusa à terceira tese]. Constantemente este erro foi cometido de um lado, censurado de outro; perceber conteúdos temporalmente sucessivos, isso não quer dizer perceber conteúdos enquanto temporalmente sucessivos"21 [recusa à segunda tese, que é derivada da terceira] (grifo nosso). Exemplificando, "meu olhar erra aos arredores em direções diferentes, fixando ora tal objeto, ora outro, e suscitando assim múltiplas representaçōes sucessivas. Mas um interesse particular é necessário para que seja retida por ela mesma a sucessão temporal" 22

Em decorrência dessas recusas, citaremos inteiramente a tese que Husserl formulará:

Se se tratasse somente de descrever o fenômeno que há quando nós nos representamos uma quantidade, então nós certamente deveríamos fazer menção das modificações temporais que conservam os conteúdos singulares, mesmo que em regra geral elas não façam ao objeto uma atenção particular. Se há na nossa representação um conjunto de objetos A, B, C, D então por ligação ao processo sucessivo pelo qual se forma o todo, $D$ não é talvez dado finalmente senão enquanto representação sensível, enquanto que os outros conteúdos são simplesmente enquanto representações imaginárias, de uma maneira que é modificada no que concerne o tempo e também alias no que concerne ao conteúdo. Se no inverso nós vamos de $\mathrm{D}$ a $\mathrm{A}$, o fenômeno então é outro. A significação lógica ultrapassa (aufhebt) todas estas diferenças. Os conteúdos modificados servem de signos, de substitutos para estes que não foram modificados. [Porém] no

\footnotetext{
${ }^{20}$ Ibidem, p. 37.

${ }^{21}$ Ibidem, p. 38-40.

22 Ibidem, p. 38.
} 
momento que nós construímos a representação do conjunto, quando o 'por em coleção' se desenrolou, mudanças se produziram, nós visamos (meinen) retê-los efetivamente e unificá-los, e assim o conteúdo lógico desta representação não é, por exemplo, $\mathrm{D}$, [ou] C que acabou de ocorrer, [ou] B que tinha ocorrido mais cedo, [ou] até $\mathrm{A}$ que sofreu a mais forte mudança, mas ele [o conteúdo] não é nada senão $(A, B, C, D)$; a representação se encarrega de cada um dos conteúdos singulares sem se ocupar das diferenças temporais nem [mesmo] de ordem temporal que se funde acima. ${ }^{23}$

Citamos este trecho todo porque é precisamente ele que rejeita o conceito temporal de "número" que teve sua tradição iniciada por Kant e que ainda influenciava a psicologia. A sucessão temporal não pode servir de base porque ela já trata os fenômenos como representações ou representados.

(...) É necessário, quando mesmo em geral, fazer uma distinção entre o fenômeno enquanto tal e este ao qual ele nos serve ou o que ele nos significa (was es uns bedeutet); e, por conseguinte também entre a descrição psicológica de um fenômeno e a indicação de sua significação. $O$ fenômeno é a base da significação, mas ele não é a significação ela mesma. ${ }^{24}$

Apesar da recusa às teorias do número como representação temporal ser a mais difícil, Husserl criticará, também, F. A. Lange, intelectual que desenvolveu uma explicação do "número" pela "síntese espacial" e pela "síntese coletiva" Sobre a "síntese espacial", Husserl a recusa imediatamente. "Duas maçãs continuam duas maçãs, que nós as desloquemos para a direita ou para a esquerda, para o alto ou para baixo. $O$ número não tem precisamente nada a ver com a situação espacial" 25

Mas sobre a "síntese coletiva" ou "arquétipo das grandezas discretas" (como define Lange) são mais interessantes e fazem Husserl

${ }^{23}$ Ibidem, p. 46.

${ }^{24}$ Ibidem, p. 48.

${ }^{25}$ Ibidem, p. 49. 
refletir se essa síntese seria como uma similitude típica (bildlich) entre grandezas como quantidade e número que consistiria em um ato psíquico que unificaria parte em um conteúdo de intenção espacial. Porém Husserl não tarda em perceber o equívoco que houve a respeito do termo síntese desde que Kant o definiu como o que "significa ao mesmo tempo o ato de ligar (a atividade de ligação) e o resultado do ato de ligar (o conteúdo da ligação)" ${ }^{26}$ Segundo Kant, "o conceito de síntese não é adquirido por abstração a partir de conteúdos primários, mas somente por referência à atividade de ligação do entendimento" ${ }^{27}$ Lange percebeu essa confusão de Kant no âmbito da experiência espacial e tentou corrigir o conceito de síntese apenas negando o de Kant: "nós adquirimos a representação da ligação do mesmo modo que toda outra representação, por análise e por abstração a partir dos conteúdos primários" ${ }^{28}$ Lange permaneceu, desse modo, ainda na atitude natural, pois apesar de discordar de Kant, ele manteve o conceito nos mesmos termos psicologistas, estes que indevidamente "são deslocados ao fundo transcendental da vida que precede a consciência", ${ }^{29}$ mas onde nunca Lange deveria tê-los colocado. Para Husserl, as ligações dos conteúdos não são primeiramente dados por uma atividade espontânea do entendimento, nem pela abstração dos conteúdos simples; as ligações, quando se formam pela primeira vez, simplesmente ocorrem. Mas nada impede que, depois, por meio de um outro tipo de ligação, possa se criar ou religar. Criação só existe no âmbito da atividade mental. "Certamente, distingue-se de uma maneira inteiramente geral a atividade mental que religa, da relação ela mesma (por exemplo, o ato de igualar, da igualdade, etc.)" 30

\footnotetext{
${ }^{26}$ Ibidem, p. 50.

27 Ibidem.

${ }^{28}$ Ibidem, p. 53.

${ }^{29}$ Ibidem, p. 57.

${ }^{30}$ Ibidem, p. 68.
} 
Mas a ligação coletiva de Husserl, que ocorre no fundo transcendental das relações em geral, não deve ser confundida, por exemplo, com a "intuição psíquica interna" de Baumann. É verdade que para que os numerais surgissem pela primeira vez a partir de uma mente humana foi preciso uma criação mental, mas se tornados convenções, não há depois necessidade - no e para o fundo transcendental da experiência interna - de mais nenhuma criação. "De um lado os números devem ser de uma certa maneira puras criações mentais; e efetivamente isso é exato já que os números dependem de atividades psíquicas que nós exercemos sobre os conteúdos". ${ }^{31}$ Mas isso não deve ser exagerado, como na tentativa de Baumann em querer fundar a base da enumeração pela idéia de intuição interna do espaço por abstração do mundo exterior. Isso é novamente cair em uma atitude naturalista da experiência primária. O conceito de "número" não tem nada a ver com o de "espaço", a "intuição" do conjunto espacial não pode ser a intuição coletiva ela mesma.

Que também não se confunda a "ligação coletiva" de Husserl como se fosse uma dupla representação: da diferença ou distinção entre os objetos e da identidade de cada objeto com ele mesmo. Defensores dessa posição são Jevons, Sigwart e Shuppe e, para eles, "número" é ora uma representação da pluralidade ou das marcas distintivas dos elementos de um conjunto ora a forma vazia da diferença. É claro que será sempre possível já no âmbito simbólico querer distinguir objetos, "nós temos sempre o direito de nos fundar sobre os conteúdos singulares para formular juízos evidentes que enunciem que cada um dos

${ }^{31}$ Utilizamos o termo "passível de" para indicar que o juízo de "diferença" não exige necessariamente atenção aos conteúdos para distingui-los, há, por exemplo, a representação concreta do conjunto, na qual "é somente exigido que cada um dos conteúdos que ela carrega seja notável por ela mesma, que ele seja separado; todavia não é absolutamente necessário fazer atenção às distinções de conteúdos, mesmo que muito freqüentemente isso possa se produzir" Cf. p. $72 \mathrm{da}$ "Filosofia da Aritmética". Mas mesmo assim, essa representação concreta está ainda na atitude natural. 
conteúdos é diferente de cada outro; mas não é certo que devamos formular estes juízos", 32 A "diferença" não é fundamento do "número", mas também não é um conteúdo notável ou posicional. Ela é apenas um juízo negativo sobre conteúdos passíveis ${ }^{33}$ de tal juízo (no caso, conteúdos diferentes). Sobre a "diferença" vê-se também que não é um ato do entendimento como o termo "análise" pode evocar, é somente um juízo que só se realiza a partir de conteúdo passível de distinção.

Salienta Husserl também que todas essas críticas à teoria da "distinção" vale para a da "identidade" Nenhuma delas pode servir de fundamento à enumeração, a enumeração é uma atitude mental completamente distinta. A conclusão parcial a qual Husserl pode chegar então é que "a experiência interna não nos mostra absolutamente semelhantes atividades de juízo pelas quais os conteúdos singulares deveriam ser apreendidos como distintos eles dos outros quando nós os enumeramos; ela mostra, ainda menos, traços destas distinções de ordem superior", 34

Fica claro então que a investigação husserliana deparará com a esfera dos fenômenos aos quais deve haver uma representação unitária que os ligue a um conjunto. Essa ligação é "a coleção [que] não pressupõe nenhuma espécie de comparação. Quando nós pensamos, por exemplo, o conjunto formado pelo pendulo, a tinta e a pluma, não precisamos começar por comparar estes conteúdos; ao contrário: para poder fazer isto devemos já os ter colecionado" ${ }^{35}$ A ligação coletiva é então uma

${ }^{32}$ Edmund HUSSERL, op. cit., p. 73

${ }^{33}$ Ibidem, p. 81.

${ }^{34}$ Como veremos mais adiante "base" para Husserl são os fenômenos psíquicos, intencionais e complexos e "fundamento" são os fenômenos físicos, imediatos, primeiros e parciais.

${ }^{35}$ Como observa Jacques English na tradução para o francês, "contrariamente às aparências, esta palavra [Inexistenz] não quer dizer nāo-existência, mas existência-em, como presença do objeto intencionado na intentio" Cf. p. 84 da "Filosofia da Aritmética". 
relação diferente de todas as outras, ela é a base de qualquer representação e o conceito de "número" é só uma delas. É aqui então que Husserl se encontrará de frente a um tipo novo de ciência, a psicologia descritiva e essas relações como seu campo de estudo.

Em primeiro lugar, Husserl esclarecerá o termo "relação" tão obscurecido pelos tratados de psicologia. Tomemos J. St. Mill para análise: ele define "relação" como algo constituído por uma "consciência complexa" (o fundamento da relação). Para Mill não haveria necessidade de uma "base", ${ }^{36}$ isto é, de fenômenos complexos, mas apenas o "fundamento", a atividade dessa "consciência complexa" Ora, pelo contrário, na psicologia descritiva deve-se obrigatoriamente mostrar também a necessidade da atividade intencional desses fenômenos complexos para a construção de qualquer relação, e, além disso, o resultado dessa relação entre atributos relativos dos fenômenos não precisa ser complexo, mas pode ser simples antes de tudo. É nesse ponto que Husserl empresta conceitos de Brentano para caracterizar relações simples e as complexas como, respectivamente, relações de fenômenos físicos e relações de fenômenos psíquicos. Tomemos, por exemplo, a relação de "analogia": ela é uma relação física ou psíquica? Sabe-se que ela "inclui (einschliesst)... dois conteúdos eles mesmos, com qualquer caso de inexistência (Inexistenz $z^{37}$ ) intencional, e dever-se-á reconhecer que se trataria aqui de gêneros de inclusão inteiramente diferentes ${ }^{38}$ (grifo nosso)" A analogia então não é uma relação intencional, complexa, específica de segundo grau sobre um conteúdo ou algo que sirva de base para a reflexão simbólica; ela é na verdade uma relação física que não tem base, mas fundamento: os fenômenos parciais e imediatos (os dois conteúdos parciais e primários da analogia). Melhor descrevendo então a partir desse exemplo, os tipos de "relação", os fenômenos da relação física são chamados

\footnotetext{
${ }^{36}$ Idem, p. 84.

${ }^{37}$ Idem, p. 87.

${ }^{38} \mathrm{Idem}, \mathrm{p} .93$.
} 
fundamento (a parcialidade, o imediato, o não-detalhado) e os fenômenos psíquicos são nomeados base (conteúdos ou atividades intencionais, complexas). Não se deve utilizar aqui a distinção simples e composta, equívocos poderiam surgir.

Do lado da relação psíquica, seus fundamentos são os conteúdos e eles só são notáveis e representáveis justamente devido à reflexão particular psíquica da relação. É apenas nessa relação que ocorre o que Mill chamava de "colocar os conteúdos em relação uns com os outros" É preciso evitar também que se descreva essa relação psíquica como algo composto, pois quando "as circunstâncias consentem, e isso ocorre freqüentemente, nós podemos apreender com um só olhar uma igualdade entre mais de dois objetos sensíveis, sem ser devido notar a toda grande diversidade de relações simples que podem ser estabelecidas entre os objetos tomados dois por dois", ${ }^{39}$ como também concorda Stumpf em "Tonpsycologie" Logo, se o que está em jogo é uma relação psíquica, isso não quer dizer que ela já seja algo intencional ou que tenha uma "base", apesar de ser passível de acontecer.

Em segundo lugar, a teoria de Husserl terá que precisar como a ligação coletiva não se confunde com uma representação do tipo primária. A ligação coletiva não é uma "ligaçāo primária", pois ela seria falsamente como uma "ligação talvez notada intuitivamente no conteúdo da representação" Mas este caráter intuitivo já implica uma ligação complexa, um interesse, o que exatamente a ligação coletiva não é, pois esta é "ausência de ligação, relação", sendo "totalmente ilimitada e arbitrária" e, portanto, "exterior" a qualquer outra ligação ou representação de conjunto. Isso não quer dizer mais uma vez "primária", mas um "ato de notar unitário sobre o conjunto", pois está nele e com ele, e, ao mesmo tempo e no mesmo ato, o "que separa e abarca conteúdos diferentes por eles mesmos" Isto, diz Husserl, é plenamente confirmado pela experiência interna.

${ }^{39}$ Idem, p. 235. 
É verdade que Husserl admite certa transformação posterior natural e uma gradação na ligação coletiva para um "segundo grau" (por exemplo, o ato que inclui no conjunto os atos como membros) ou para um terceiro grau (como a sucessão temporal, etc.) e assim por diante. Contudo, a "relação psíquica é então uma condição psicológica prévia indispensável para toda relação e para a ligação em geral" 40 Não é necessário que toda ligação coletiva se transforme em ligação de fato (em primária ou imediata, secundária, etc.), a única necessidade é de primeiro colecionar.

Já se expôs aqui então as teses principais para se entender, no essencial, a "Filosofia da Aritmética" e algumas de suas conseqüências para a filosofia husserliana. Os enigmas que inspiraram a criação desta obra, a saber, o número e a enumeração, já foram explicados no que concerne a sua origem psicológica: eles são formados por uma ligação coletiva e são passíveis de uma representação ou re-ligação psíquica que os transforma na única forma possível: símbolos e signos. A região e a representação que diz respeito ao conteúdo fenomenal do número é a psíquica e sua forma particular é a simbólica (forma que seria reformulada em uma aritmética nova, exposta um pouco na segunda parte e nos apêndices do livro, mas que seria definitiva no tomo II - porém não publicado pelo próprio Husserl). Mas por que o autor não dedicou o resto de sua vida nessa tarefa?

Quase que "por acaso" Husserl teve de passar por uma análise de outro tipo de fenômeno que não o simbólico (como o número) e estudar também o âmbito dos fenômenos imediatos, primários, parciais, de fundamentos, isto é, fenômenos que visam e depois se referem a conteúdos sensíveis, brutos, do mundo exterior. Aplica-se sobre essa região também o conceito de ligação coletiva. Mas quais seriam os

${ }^{40}$ Idem, Idéia da Fenomenologia, Edições 70, Lisboa, 1986, p. 32. 
mecanismos de relações nesse mundo da experiência sensível? Essa esfera seria importante para a filosofia que Husserl se propõe?

$\mathrm{Na}$ segunda parte da "Filosofia da Aritmética", o autor tentará explicar - depois de ter elucidado a origem do número e da enumeração - o conteúdo e as relações de conteúdo dentro da aritmética, ou seja, dentro do cálculo simbólico. Husserl não conseguirá se restringir ao cálculo, à técnica, exatamente porque ela é somente simbolização do horizonte que carece a todo o momento de maiores explicações sobre sua origem fenomenal. "Toda a aritmética não é nada diferente, nós veremos, de uma soma de meios artificiais para vencer as imperfeições essenciais de nosso intelecto mencionado aqui" ${ }^{41}$ Contudo, Husserl conservará os ganhos teóricos do exame sobre a origem psicológica da aritmética, os conceitos serão apenas um pouco modificados. "Fenômeno imediato" e "intencionalidade" das relaçōes psíquicas serão abundantemente úteis. $\mathrm{E}$ foi por isso então que a aritmética pôde ser empregada como instrumento de reflexão filosófica e isso certamente é o principal motivo da obsessão de Husserl em fazer da filosofia uma ciência de rigor, uma fenomenologia.

Não se poderia certamente negar a importância filosófica da aritmética como ciência de rigor depois do diálogo exaustivo e perseverante de Husserl contra os psicologistas tanto da filosofia científica como da matemática. Na "Filosofia da Aritmética", foi mostrado como uma crítica sobre a origem dos fenômenos e das relações psíquicas subentendidas por uma lógica do cálculo aritmético deve ser absolutamente necessária. Foi na "Idéia da Fenomenologia" que se fez também a crítica às metafísicas, à psicologia e às teorias do conhecimento até então utilizadas para descrever o psíquico. Já feita a crítica à lógica matemática a esse respeito, faltava fazer a segunda, nas lições de 1907, para depois justificar a filosofia como atitude científica de rigor em 1911. Só agora então as teses que lançamos no começo deste texto sobre a "Idéia da fenomenologia" fazem um sentido, pois, acrescenta-

41 Ibidem, p. 33. 
da à crítica ontológica da obra acima citada nossa análise da "Filosofia da Aritmética" como interrogação sobre a origem da ciência matemática, elas vêm por justificar a filosofia como a ciência da qual se fala sobre ciência. Para Husserl, fazer filosofia só pode ser rigorosamente fazer ciência das ciências.

\section{Análise da "Idéia da Fenomenologia"}

A idéia principal da obra é a seguinte: se o psicologismo preza o método empírico, a filosofia tida como ciência rigorosa deve se guiar pela crítica do conhecimento. Para Husserl, o pensamento filosófico não deve se reduzir às premissas naturais e empíricas para adquirir um estatuto científico, pois o rigor não está no procedimento das ciências naturais, mas é a filosofia fenomenológica que define a essência ou estrutura necessária dos objetos da ciência. Por conseguinte, muito ao contrário de introduzir na epistemologia filosófica um preconceito ou premissa naturalista para somente se preocupar com as coisas em si e seus efeitos, a ciência precisa de uma base filosófica na qual seja em primeiro lugar examinada a possibilidade de conhecimento em atingir fenômenos.

Porém, o psicologismo julga impossível uma teoria filosófica se iniciar se os seus próprios fundamentos são postos em questão. Pois se é possível duvidar dos pressupostos filosóficos, por que não substituílos por um método naturalista? Para Husserl, só se verifica que alguns princípios filosóficos são indubitáveis se suas possibilidades cognitivas são postas em questão. Um exemplo é a posse da vivência indubitável da cogitatio cartesiana enquanto se experimenta e sobre ela se reflete. Ela não é uma prova de que o eu psicológico existe como querem os naturalistas, pois mesmo que essa intuição clara tenha uma intenção, ou uma imanência real (essência humana), ainda assim ela não é algo transcendente, que está no mundo. Se se quer enxergar o que há de indubitável, autodado de modo completo e inteiramente adequado, é preciso notar o que há de imanente no fenômeno. 
Para então analisar a imanência e a intencionalidade pura da consciência, é preciso fazer uma redução fenomenológica. Trata-se de reduzir metodologicamente do campo da transcendência, realidade, existência, suas respectivas essências. Notamos então que existe a possibilidade das essências, não se trata de reduzi-las a não possibilidade ou a não existência pela visão psicologista de que se a possibilidade do conhecimento objetivo é obvia, ou seja, em última análise elas não existiriam e não se deveria levá-las em conta. E essa é a distinção entre fenomenologia e psicologia, pois esta não lida com o reduzido, isto é, mas tentar estudar a percepção natural da vivência do eu no tempo objetivo ou transcendente.

Portanto, se à fundamentação da ciência é preciso, segundo Husserl, não considerar o conhecimento como em parte já explicado, logo, criticar a possibilidade do conhecimento em geral - e mais, excluir todas as posições transcendentes por uma redução - a psicologia, esta ciência objetivante, não tem legitimidade para dar sentido aos princípios da filosofia e da ciência. Não obstante, se o psicologismo tenta equivaler o âmbito filosófico a uma psicologia, Husserl, por outro lado, não rivaliza com a psicologia ela mesma; pois é claro que é importante haver uma ciência do psíquico no sentido empírico, desde que ela não admita o caráter físico da consciência como única determinação possível.

A fenomenologia, ciência das essências, está anterior a uma ciência objetiva da consciência, e é justamente por isso que a atitude psicologista deve ser coibida na filosofia, pois ela confunde a dimensão essencial do fenômeno puro do conhecimento com suas determinações objetivas e empíricas. A psicologia descritiva que temos em mãos, por assim dizer, necessitará de um respaldo filosófico que possa, por meio de uma redução fenomenológica, atingir a pureza e a imanência e assim delimitar o eidos ou essência dessa ciência, bem como das demais.

Mas como é possível que a base de toda a ciência tenha como forma algo tão diminuto como esses fenômenos reduzidos a suas singularidades absolutas, que não são objetivas? Como é possível nascer 
uma verdadeira psicologia descritiva da fenomenologia se ela, por sua redução da consciência em si às intuições e operações lógicas, não oferece esses dados com evidencia perceptiva? A peculiaridade da fenomenologia é mesmo a abstração ideativa, não com base no visto, mas no puro ver, no puro intuir. Contudo, ela não intui somente a imanência inclusa ao fenômeno, mas também a imanência real que visa o verdadeiramente transcendente, mas por segurança metódica o transcendente em geral deve ser posto em questão. Ou seja, se por definição a essência do fenômeno não abrange uma objetividade, não se nega completamente a capacidade de ele transcender a si mesmo. Por fim, cabe observar que a fenomenologia delimita as ciências, porém o seu método de descoberta não é o mesmo delas.

O que o psicologismo não concebe é o porquê do tratamento fenomenológico concentrado sobre a imanência inclusa se o que está dado em si, o objeto, é uma continuidade inseparável da essência. Em concordância agora com o psicologismo, Husserl confessa que em alguns casos podemos encontrar "também no fenômeno da percepção o mesmo que encontrávamos na consciência da universalidade, a saber, é uma consciência que constitui um dado que em si mesmo se dá, que não está contido no incluso e não é em geral para encontrar como cogitatio" 42 Mas se a psicologia teoriza bem que as coisas percebidas são inseparáveis do fenômeno, cabe à fenomenologia revela que elas "são como individualmente separáveis do fenômeno, mas essencialmente são deles inseparáveis" ${ }^{43} \mathrm{O}$ psicologismo não pode limitar o alcance fenomenológico simplesmente criticando o puro intuir, pois a tarefa da fenomenologia é também captar o objeto real transcendente (o que de início era visado) identificando gradualmente todas as formas do "dar-se em si mesmo", que tem seus nexos como "unidades do conhecimento e como unidades cognitivas, têm também os seus correlatos objetivos unitários" 44

\footnotetext{
42 Idem.

${ }^{43}$ Falta texto nota 43 e 44
} 
Se Husserl então entende por fenomenologia também uma "ciência das objetividades cognitivas", ela não se torna um tipo de psicologia? Embora ambas tentem resolver o problema da correlação entre conhecimento e seu objeto, a fundação da fenomenologia não é uma psicologia (pelo menos na "Idéia da Fenomenologia") porque elas não lidam com os mesmos graus do problema, a saber, o nível críticocognitivo e a exatidão experimental. As necessidades de cada uma são diferentes: a psicologia procura proposiçōes válidas universalizando a região natural para estudá-la, a fenomenologia busca afastar o ceticismo e o solipcismo da ciência objetiva por um exame da possibilidade de conhecimento nas ciências naturais e na lógica.

O que não faz da fenomenologia uma certa psicologia é sua preocupação em não considerar óbvia a possibilidade do conhecimento. Só a maneira de uma crítica do conhecimento, ou seja, de um rigor científico, a ciência é obrigada a não tomar como a explicação total entre o objeto e conhecimento a mera constatação de fatos e mudanças das vivências dos indivíduos psíquicos.

A questão que agora se põe é por que a psicologia, se se quer rigorosa, deve apenas pelo anterior julgamento deixar de fundamentar a ciência? Como se justifica esse julgamento metodológico?

$\mathrm{Na}$ verdade, o que Husserl entrevê com uma crítica do conhecimento é a abertura de um espaço para que se possa provar a existência de diversas complicações na referência do sujeito ao objeto, isto é, ampliar a base da ciência primeira para que ela possa ser rigorosamente suficiente e completa; e não há por que não cobrá-la disso. O que fica obscuro é por que uma crítica cognitiva deve apontar necessariamente ao estudo das essências. Já falamos anteriormente que isso fica ambíguo, visto que a psicologia supõe uma continuidade entre a essência e o objeto. Para a isso responder, é necessário considerar primeiramente que a psicologia e as ciências exatas, as quais apesar de pressuporem a possibilidade do conhecimento como óbvia, elas trabalham com o progresso experimental, ou seja, são conscientes em admitir o conhecimento da transcendência ou da objetalidade não é 
óbvio, não é dado completamente. Em segundo lugar, podemos então perguntar: o que elas possuem como conteúdo lógico ou clarividência legitimadora para verificar suas descobertas objetivas? É por isso então, de acordo com Husserl, que se encontra a necessidade de se estudar primeiramente e profundamente o campo das essências, o puro ver ou captar, a imanência da consciência.

Uma outra observação: para Husserl, não podemos ser ingênuos em duvidar radicalmente dos fatos do mundo, o fato (Das) mundano é absolutamente seguro, é o campo da ciência. A transcendência que Husserl coloca em questão na crítica do conhecimento é a científica ou cognitiva, mas não a existência do mundo. O enigmático é o como da transcendência. Essa é a peculiaridade da crítica cognitiva husserliana frente à cartesiana. Podemos dizer que é uma quase inversão dela: enquanto Descartes crê na validade do princípio epistemológico essencial da evidência clara e distinta e coloca o mundo em suspensão de juízo, Husserl admite a realização e existência das ciências objetivas, mas a partir de uma dúvida quanto ao rigor delas é que se chega à legitimação do estudo das essências, as quais, é importante dizer, nunca tinham sido analisadas em toda sua complexidade imanente. A inversão não é total porque Husserl também considera os princípios lógicos (entre eles a simplicidade da intuição e idealidade da evidencia da verdade) como imprescindíveis à apoditicidade da verdade.

Apesar de Husserl também analisar o rigor das ciências como fez Kant, não se trata da mesma crítica, pois para Kant a crítica não repercute só em uma investigação das essências, mas em saber como são possíveis juízos sintéticos a priori nos princípios de uma verdadeira filosofia que objetive o mundo ou fenômeno. Embora em Husserl os fenômenos tenham uma intencionalidade, não se trata absolutamente de uma síntese, a qual recorre ao auxílio da intuição sensível kantiana. Se Husserl, depois de feita a crítica, investiga a consciência como de início fez Descartes, Kant começa pelo problema de Hume, o qual não admitia sínteses com as determinações subjetivas. 
Para o psicologismo, só as transcendências devem (de preferência) fundamentar e explicar posições transcendentes. Husserl assegura que a idealidade pura da fenomenologia é capaz de fundamentar a transcendência porque não se estuda somente a transcendência universal que decorre da imanência inclusa, mas também a intencionalidade transcendente singular que vem da determinação da imanência real. Não é ilegítimo tomar como absoluto uma transcendência singular, desde que ela seja clara e distinta, como uma cogitatio.

Já separamos então a fenomenologia da psicologia pelo menos através de suas delimitações exteriores. Adentremos nos detalhes interiores da fenomenologia na Quinta Lição, a qual discute a constituição da consciência no tempo, tema que é um dos mais importantes para a psicologia objetivante. Analisando a constituição da consciência no tempo, Husserl expõe na Quinta Lição uma contraproposta ao psicologismo, um esboço de uma teoria do conhecimento, resumidamente: em primeiro lugar, os atos categoriais, isto é, os conectivos lógicos de predicação e atribuição, as constantes lógicas, a confirmação, verificação e seus opostos são sempre pressupostos dos enunciados sintéticos evidentes. Esses atos categoriais são constituídos por dados genuínos, os estados de coisas ontológicas, estes que por fim são inseparáveis intencionalmente aos atos de pensamento, os quais não são caixas de dados, mas a consciência intencional que vê, onde acontece o puro ver.

Percebe-se por fim que entre as três obras do nosso tema não se nota apenas uma crítica ao psicologismo, mas a delimitação da ciência fenomenológica e seu campo de atuação. Não se trata apenas de um combate às conseqüências filosóficas do psicologismo, mas o esboço de uma contraproposta desde os princípios. 


\section{Bibliografia}

HUSSERL, E. Ideen zu einer reinen Phänomenologie und phänomenologischen Philosophie. In Jahrbuch für Philosophie und phänomenologische Forschung, Halle, Max Niemeyer, 1913.

. Die Idee der Phänomenologie. Fünf Vorlesungen. Editado por Walter Biemel. Hague, Martinus Nijhoff, 1973.

. "Philosophie als strenge Wissenschaft." In: Logos 1, Tübingen, 1910-11. . Philosophie der Arithmetik. Pyschologische und logische Untersuchungen. Erster Band. Halle-Saale, C.E. M. Pfeffer (Robert Stricker), 1891.

. Logische Untersuchungen. Halle, Max Niemeyer, 1900-1901.

. Filosofia como ciência de rigor, Coimbra, Ed. Atlântida, 1952.

. Philosophie de l'Aritméthique, Paris, Presses Universitaires de France, 1972.

. Idéia da Fenomenologia, Edições 70, Lisboa, 1986. 